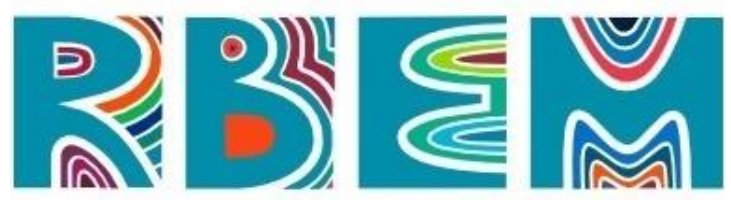

REVISTA BAIANA dE EDUCAÇÃo MATEMÁtica

ARTIGO

dol https://doi.org/10.47207/rbem.v2i01.12166

\title{
Estágio Supervisionado na Formação Inicial de Professores de Matemática: limites e possibilidades
}

\author{
PIRES, Maria Auxiliadora Lisboa Moreno \\ Universidade Estadual de Feira de Santana (UEFS). Doutora em Educação pela Universidade Federal do Rio \\ Grande do Norte (UFRN). ORCID: https://orcid.org/0000-0001-9070-5730. E-mail: malmpires@uefs.br.
}

\section{MENDES, Iran Abreu}

Universidade Federal do Pará (UFPA). Doutor em Educação pela Universidade Federal do Rio Grande do Norte. ORCID: https://orcid.org/0000-0001-7910-1602. E-mail: iamendes1@ gmail.com.

Resumo: O estudo tem por objetivo discutir as demandas atuais de professores que ensinam Matemática num cenário de pandemia onde foram trabalhadas duas perspectivas: o Estágio Curricular Supervisionado na formação inicial do professor de Matemática e o desenvolvimento profissional desses futuros professores. Essencial destacar o processo da formação inicial do futuro professor de Matemática que passa por profundas mudanças em virtude de um conjunto de fatores impactados pela pelas novas demandas da sociedade, incluindose as expectativas das escolas em relação ao ensino-aprendizagem da Matemática. Trata-se de um estudo do mapeamento das principais tendências apontadas por especialistas em trabalhos recentes divulgados na internet $\mathrm{e}$ na literatura sobre a formação de professores de modo geral. Para análise, recorreu-se a um conjunto de documentos, sendo alguns digitais, além de outras fontes como publicações atualizadas de jornais e revistas do país, documentos oficiais do Ministério de Educação e dos sindicatos de professores de alguns estados. O estudo contribuiu para a reflexão e divulgação de alternativas metodológicas para o ensino de Matemática em ambiente de aprendizagem virtual, nos tempos atuais

Palavras chave: Estágio Supervisionado. Aulas remotas. Ambiente de Aprendizagem virtual.

\section{Supervised Internship in Initial Mathematics Teacher Training: limits and possibilities}

\begin{abstract}
The study aims to discuss the current demands of teachers who teach Mathematics in a pandemic scenario where two perspectives were worked: the Supervised Curricular Internship in the initial training of Mathematics teachers and the professional development of these future teachers. It is essential to highlight the initial training process of the future Mathematics teacher, which undergoes profound changes due to a set of factors impacted by the new demands of society, including the expectations of schools in relation to teaching-learning Mathematics. This is a mapping study of the main trends pointed out by specialists in recent works published on the internet in the literature on teacher education in general. For analysis, a set of documents was used, some of which were digital, in addition to other sources such as up-to-date publications from newspapers and magazines in the country, official documents from the Ministry of Education and from the teachers' unions in some states. The study contributed to the reflection and dissemination of methodological alternatives for the teaching of Mathematics in a virtual learning environment, in current times.
\end{abstract}

Keywords: Supervised Internship. Remote classes. Virtual Learning Environment. 


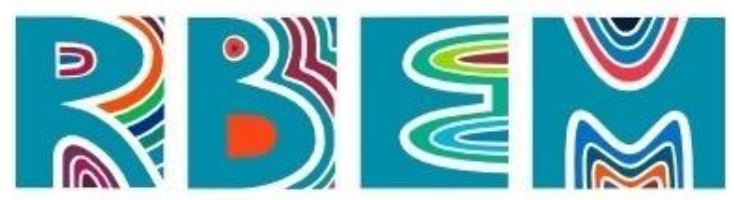

REVISTA BAIANA DE EDUCAÇÃO MATEMÁTICA

\title{
Pasantía supervisada en la formación inicial del profesorado de matemáticas: límites y posibilidades
}

\begin{abstract}
Resumen: El estudio tiene como objetivo discutir las demandas actuales de los docentes que imparten Matemáticas en un escenario pandémico donde se trabajaron dos perspectivas: la Pasantía Curricular Supervisada en la formación inicial de docentes de Matemáticas y el desarrollo profesional de estos futuros docentes. Es fundamental resaltar el proceso de formación inicial del futuro docente de Matemáticas, que está experimentando profundos cambios debido a un conjunto de factores impactados por las nuevas demandas de la sociedad, incluyendo las expectativas de las escuelas en relación a la enseñanza-aprendizaje de las Matemáticas. Se trata de un estudio del mapeo de las principales tendencias señaladas por especialistas en trabajos recientes publicados en Internet en la literatura sobre la formación del profesorado en general. Para el análisis se utilizó un conjunto de documentos, algunos de los cuales eran digitales, además de otras fuentes como publicaciones actualizadas de periódicos y revistas del país, documentos oficiales del Ministerio de Educación y sindicatos de docentes de algunos países. estados. El estudio contribuyó a la reflexión y difusión de alternativas metodológicas para la enseñanza de las Matemáticas en un entorno de aprendizaje virtual, en los tiempos actuales.
\end{abstract}

Palavras-Clave: Pasantía supervisada. Clases remotas. Ambiente de aprendizaje virtual.

\section{Introdução}

O ensino de Matemática e a sua translação para a prática em sala de aula, nos variados contextos requer a adoção de estratégias através da reflexão sobre a realidade presente nos dias atuais. GATTI (2020) nos aponta pontos de reflexões balizados por uma sensibilidade frente ao momento que estamos vivendo: somos planetários e tudo que existe no planeta nos afeta. Os números são impressionantes numa escala crescente, alarmante para todos nós, nesse cenário de pandemia que atinge igualmente todos, pobres e ricos sem desconhecer por certo que em contextos variados os já então desassistidos pelo Estado, agora seguem abandonados à margem do acesso aos cuidados básicos de saúde, higiene e alimentar que precisam para o enfrentamento da pandemia. Milhares perderam os empregos, a economia se retrai deixando um rastro de perdas de sonhos e esperanças.

Nós professores de Matemática e futuros professores talvez, mais familiarizados com o trato diário na nossa profissão, com números, grandezas, medidas, progressões geométricas, gráficos, tratamentos da informação, estatísticas, percebemos mais facilmente os significados de curvas ascendentes nos gráficos, no atual cenário. O esgotamento de cidades, municípios, estados e países na tentativa de controle do vírus que se alastra pelo nosso planeta. Somos desafiados a proteger nossa espécie para garantirmos a sobrevivência de todos. A Organização Mundial da Saúde (OMS), alertou a todos sobre a pandemia para o Covid-19, infecção causada pelo novo corona vírus e suas variantes, e a disseminação mundial dessa nova 


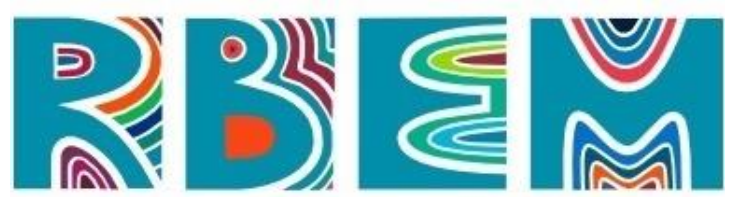

REVISTA BAIANA DE EDUCAÇÃO MATEMÁTICA

doença. Pandemia que se espalha por diferentes continentes com transmissão sustentada de pessoa para pessoa, se espalhando no ar.

Atualmente, há mais de 120 países com casos declarados da infecção. Estamos falando de uma dimensão geográfica global rápida que o vírus tem apresentado. Temos certeza que nada mais será como antes. $\mathrm{O}$ mundo mudou, a vida se transformou numa velocidade que colocou paradoxalmente estupefatos todos nós, conectados e desconectados com menos ou mais tecnologias, ou seja, os que têm acesso e os sem acesso algum, aos meios e ferramentas digitais. Tudo é concreto, urgente e desafiador. Em contextos mais específicos com milhares de estudantes fora da escola, somos intimados a ampliar nossas fronteiras de atuação buscando dominar métodos, metodologias de aproximação com o objeto de ensino da nossa área, a Matemática e o compartilhamento dessa ciência com nossos alunos.

Segundo dados ainda divulgados pela Organização Mundial da Saúde (OMS), há uma preocupação geral com os impactos da crise gerada pela pandemia do corona vírus na área da educação. A OMS estima que a pandemia possa retirar 9,7 milhões de crianças da escola até o final do ano. O aumento da pobreza, além dos cortes orçamentários quase em todos os setores da sociedade civil, do público ao privado, inclusive com o fechamento de comércios, o desemprego e a falta de trabalho para os trabalhadores autônomos, informais aprofundam a extrema desigualdade social, além de evidenciar mais e mais a concentração de riquezas por alguns poucos.

Vivemos o medo generalizado do inimigo invisível, em um cenário caótico onde a imprevisibilidade predomina no pensar o amanhã. Como não pensar solidariamente, além do próprio umbigo, o que significa isolamento social para tantos que precisam ganhar o seu sustento no dia a dia das cidades, das feiras, esquinas e mercados agora vazios? Como destaca SANTOS (2020) “como resolverão o conflito entre o dever de alimentar a família e o dever de proteger as suas vidas e a vida desta? Morrer de vírus ou morrer de fome, eis a opção”. Mais ainda, "quem tem fome não pode ter a veleidade de comprar sabão e água a preços que começam a sofrer o peso da especulação. Noutros contextos, os uberizados da economia informal que entregam comida e encomendas ao domicílio?” Os desafios nos tempos atuais são enormes também para os professores, de todas as áreas do conhecimento. Desconheço quais profissionais tenham enfrentado tantos desafios, tantas situações complexas como os professores. A docência é uma profissão complexa. 


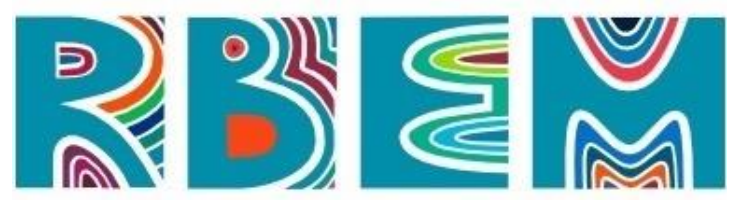

REVISTA BAIANA DE EDUCAÇÃO MATEMÁTICA

Enquanto professores de Matemática, atuando em turmas do Estágio Curricular Supervisionado (ECS), disciplinas de Ensino Remoto Emergencial (ERE), partimos para esta investigação ciente que todos nós, os professores, devem possuir um conceito amplo de ensino, que ultrapasse uma visão conservadora, no sentido de desenvolverem competências para intervenção nos diferentes contextos de ensino, na pandemia. A formação inicial do professor determina a utilização de estratégias de ensino que visem, além do processo do conhecimento técnico, específico da área, à prática reflexiva, o que justifica o aprofundamento dos assuntos abordados durante a sua formação, com metodologias inovadoras que potenciem maior reflexão sobre o ensino.

A discussão sobre as demandas atuais para professores que ensinam Matemática num cenário de pandemia, foi realizada a partir do mapeamento na internet de pesquisas e estudos sobre a utilização de recursos tecnológicos para aulas remotas, o que fortalece a necessidade de reflexão sobre o papel do ECS nos tempos atuais, de muitos desafios, de erros e acertos, de limites e possibilidades. Buscamos igualmente investigar como o ECS é definido e tratado no momento privilegiado da formação do futuro professor, explicitando como o ECS acontece e vem sendo construído na formação inicial do professor de Matemática principalmente considerando o cenário caótico, fragmentado e complicado que estamos vivenciando.

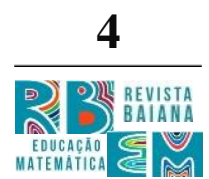

Temos por um lado, o ECS como espaço da formação inicial configurado nos Projetos Pedagógicos dos cursos de Licenciatura em Matemática, que coloca o ECS como componente fundamental da formação do futuro professor de Matemática. Espaço esse, comprometido com os interesses, necessidades e condições de funcionamento da escola pública. Em tempos de pandemia, tivemos a redução abrupta dessas estruturas com o fechamento das escolas, o que sem sombra de dúvida impactou diretamente, nas disciplinas do currículo, dos cursos de formação inicial do professor de Matemática e em particular, as que envolvem diferentes aspectos que se apresentam como cenário onde o ECS acontece nos cursos de LM e nas escolas da educação básica.

Para a realização de uma discussão maior envolvendo o ECS com a intenção de fazer emergir novas problematizações e novos conhecimentos, além de possibilitar a ampliação dos modelos de análise utilizados nos vários modos de operacionalização do ECS nas Instituições de Ensino Superior (IES), ficou claro para nós, a necessidade de aproximarmo-nos cada vez 


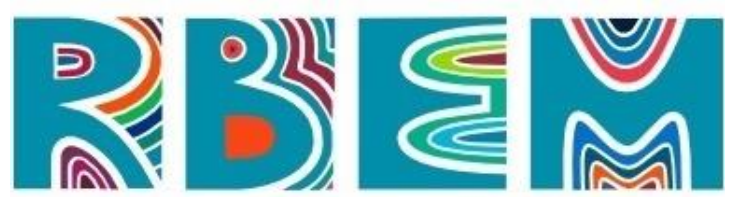

REVISTA BAIANA DE EDUCAÇÃO MATEMÁTICA

mais das escolas de Educação Básica, e das práticas dos estudantes estagiários no contexto escolar, como uma forma de escuta e reflexão sobre o que ocorre nesse contexto da pandemia.

Assim, por meio da análise de depoimentos e narrativas dos professores de Matemática, dos professores supervisores do ECS, estudantes da Licenciatura, em particular, os estudantes estagiários e os professores regentes que recebem os estudantes nas escolas de Educação Básica, foram constituídos objetos de análise para que os autores citados no quadro teórico e conceitual da pesquisa contribuíssem, de fato, para a ruptura epistemológica desejada na compreensão das formas de pensar o ECS nos cursos, no plano pessoal, aqui relacionado à construção da identidade docente e da formação e desenvolvimento profissional dos futuros professores de Matemática.

\section{Sobre a formação socioepistemológica do professor de matemática em contextos urgentes}

Este estudo focaliza, portanto, as experiências vivenciadas pelos estudantes estagiários no processo de sua formação inicial para professor de Matemática nos cursos de Licenciatura, experiências essas designadas por vários autores como prática de ensino, prática pedagógica ou estágios de ensino. Nele, particularmente, referimo-nos, sempre à formação inicial, como espaço de formação pedagógica, de construção de uma prática de ensino investigativa, de ruptura, de transição de estudantes a professores que iniciam os primeiros contatos com a realidade da escola básica, ainda nos cursos de graduação, como bem assegura GARCIA (1999). Trata-se de um período intensivo de tensões e aprendizagens em contextos geralmente desconhecidos segundo o autor. O estudo focaliza a formação inicial ainda na graduação, nas primeiras experiências docentes no período compreendido como ECS.

Sabemos que a formação inicial dos professores, tem sido objeto de diversos estudos e investigações que dizem respeito à realização de várias pesquisas sobre a capacidade atual das instituições de ensino superior, de atenderem às necessidades dessa etapa profissional. Neste sentido, também há inúmeros estudos e um intenso debate em relação à caracterização da docência como profissão comparada com outras formações, mas entrar no debate desta questão implicaria em deslocar o foco da nossa preocupação com o ECS, nos cursos de formação inicial do professor. Entretanto, não podemos deixar de considerar estas e outras questões postas nos debates atuais sobre a formação dos professores, seus processos de 


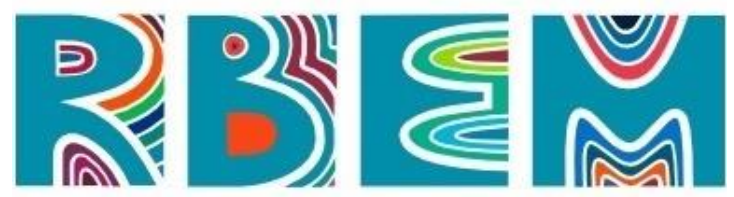

REVISTA BAIANA DE EDUCAÇÃO MATEMÁTICA

aprendizagens, uma vez que, de todas essas etapas, a que mais nos interessa é a que se inicia, voltamos a destacar, ainda, nos cursos de graduação nos primeiros contatos dos estudantes estagiários com a escola e sua complexa realidade.

Tomamos consciência das propostas de mudanças no ECS formuladas por professores e estudantes ouvidos na pesquisa, sinalizando para a urgência de soluções que revertam esse quadro fortemente apresentado na literatura, nas pesquisas mais recentes sobre a formação dos professores: o vazio entre a formação do estagiário nas IES e sua atuação nas escolas públicas de educação básica.

O diagrama a seguir auxilia na análise do ECS através do levantamento dos elementos apontados nas bases indicadas no esquema, considerando a presença ou não dessas bases, como possível indicativo de fragilidade na formação dos estagiários. A representação no diagrama do ECS parte de três elementos gerais: um corpo de conhecimento científico e tecnológico com os aportes teóricos que fundamentam a pesquisa e a formação de professores; o instrumental analítico e os estudos empíricos dos modelos, teorias e investigações sobre o ECS; e as práticas de formação que envolvem os atores (professores, estudantes e estagiários), as instituições e as experiências inovadoras.

Baseada no modelo apresentado por MERTON (1967, p. 87) sobre o paradigma proposto para a sociologia do conhecimento, ampliamos as categorias para classificação e análise de estudos na sociologia do conhecimento, enfocando as bases propriamente ditas, e não as questões formuladas pelo autor no seu esquema. As categorias, portanto, possibilitaram a indicação de resultados contraditórios, por exemplo, nas bases pedagógicas do estudo, a explicitação do instrumental conceitual atualmente em uso nos cursos de LM (bases culturais e profissionais), a determinação da natureza de problemas que têm ocupado os estudiosos (bases legais, políticas e sociais), a avaliação do material que tem sido recolhido, a indicação das lacunas e falhas características nos tipos de interpretação existentes sobre o ECS (bases sociais, culturais e pedagógicas) e as bases importantes, porém menos trabalhadas nos cursos como (bases éticas e emocionais) 


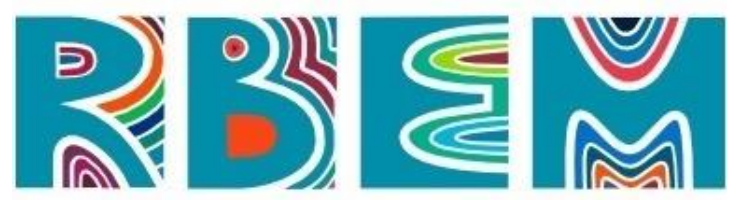

REVISTA BAIANA DE EDUCAÇÃO MATEMÁTICA

Diagrama do Estágio Curricular Supervisionado

Figura 1: Diagrama do Estágio Curricular Supervisionado nos cursos de Licenciaturas: bases, modelos e investigação.

É possível perceber a relação das bases com os componentes estruturais do ECS que de modo geral são apresentados nos componentes curriculares. Por meio do diagrama anterior, correlacionamos as bases observadas nas IES, nas escolas de educação básica com o modelo desenvolvido para auxiliar a análise, composto por três grandes blocos: um, relativo ao corpo de conhecimentos científicos e tecnológicos necessários à formação inicial do futuro professor, seguido de uma fase imediata de preparação científica, pedagógica e prática para o ECS; outro, referente ao instrumental analítico e de estudos empíricos de modelos, teorias e investigação empírica sobre o ECS; e um terceiro, sobre a prática de formação envolvendo os atores, as instituições e as experiências inovadoras.

As fases sintetizadas nos blocos, não ocorrem no curso de LM isoladamente, e sim, podem se agrupar e reagrupar com o instrumental analítico e de estudos empíricos de modelos, teorias e investigação empírica sobre o ECS, as práticas de formação envolvendo 


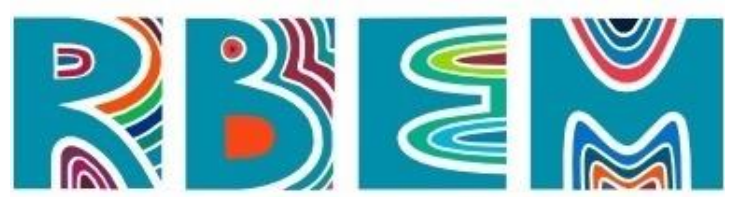

REVISTA BAIANA DE EDUCAÇÃO MATEMÁTICA

atores (estudantes, professores-supervisores) na universidade, e alunos e professores regentes nas escolas de Educação Básica no desenvolvimento de atividades apoiada pelo professor supervisor. Isso fundamentado nas bases legais, políticas, sociais, culturais, pedagógicas, profissionais presentes na formação inicial do professor de Matemática.

Os relatos das experiências vivenciadas na escola, campo do estágio, apresentam elementos que evidenciam a dinâmica do trabalho realizado, o movimento de reflexão que se estabelece com a experiência do estágio, e a sua prática em sala de aula, quando um dos estudantes estagiários participante da pesquisa diz: "O estágio foi um momento importante para o meu desenvolvimento como profissional. Permitiu uma avaliação da minha prática como educador e uma reflexão sobre a mesma, de forma que foi possível verificar em que momento e de que maneira as minhas atitudes contribuíram para o desenvolvimento do aluno. Foi também importante para o meu crescimento como estudante universitário e como futuro profissional".

Percebemos nessa fala do estudante os elementos representados no diagrama anterior, ou seja, as bases legais, políticas, sociais, pedagógicas, profissionais relacionadas com o ECS como um processo em que ocorre uma evolução natural de seu desenvolvimento no curso de Licenciatura em Matemática.

\section{Sobre o método da pesquisa}

A pesquisa se inseriu no quadro de investigações qualitativas do tipo interpretativo, em que se privilegia a interpretação na procura de significados, de compreensão mais do que uma experimentação na procura de modelos, leis (SHULMAN, 1996). Realizamos um estudo qualitativo com caráter exploratório. A referência teórica principal foram os estudos de (YIN, 2001).

O estudo foi construído a partir de um planejamento do registro das observações e práticas dos professores supervisores, dos estudantes estagiários de Matemática. Os elementos constituídos para estudos, envolveram estudantes estagiários dos cursos de Matemática em situações de ensino nas escolas, em situações de aprendizagem no curso de licenciatura em matemática nas universidades. A pesquisa envolveu 38 estudantes estagiários, distribuídos pelas instituições professores regentes que recebem os estudantes estagiários, nas escolas de educação básica. Foram utilizados os seguintes instrumentos: questionários enviados para 


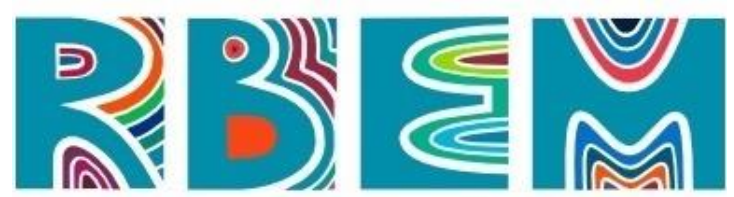

REVISTA BAIANA DE EDUCAÇÃO MATEMÁTICA

preenchimento pelos professores de Matemática, autores, supervisores, recém-egressos dos cursos de Licenciatura em Matemática, coordenadores de cursos, professores aposentados, professores de matemática de outras unidades federativas do país, via e-mail; questionários aplicados aos estudantes estagiários das IES pelos pesquisadores; questionários aplicados aos professores regentes que recebem os estudantes estagiários nas escolas públicas.

Acrescentamos as grelhas de observação de aulas dos estudantes estagiários (grelha de registro do pesquisador durante as aulas de observação dos estudantes estagiários nas escolas). Foram analisados os planejamentos das aulas, práticas pedagógicas e estratégias de aprendizagem.

Realizamos entrevistas semiestruturadas com os professores e estudantes estagiários dos cursos de Licenciatura em Matemática. Analisamos os memoriais de três professores supervisores de ECS em atividade nas instituições de ensino superior, como também, os relatórios de conclusão do ECS dos estudantes estagiários. Alguns fragmentos da análise realizada apontam que $34 \%$ dos estudantes estagiários das três instituições pesquisadas declararam o desejo de adquirir mais experiência profissional durante o ECS e ampliar os seus conhecimentos e $18 \%$ deles pretende colocar em prática o que aprenderam no curso. Para o professor de Matemática autor, um desabafo, o ECS precisa ser interpretado como fazendo

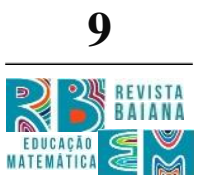
parte da licenciatura, de fato, e não um apêndice que ocorre a partir da segunda metade do curso. É fundamental que todos os docentes do curso estejam envolvidos no projeto pedagógico de estágio.

Entre as falas recolhidas destacamos: Regente que recebem os estagiários na escola de educação básica: "quanto a mim, como professora que recebe o estagiário na escola, procuro o máximo está próximo as orientações que deveriam trazer da Universidade”.

E um depoimento forte de uma jovem professora: "A Matemática que se estuda em um curso de Matemática, está voltada para uma ciência pura e com poucas aplicações. Isso torna a formação do professor também pouco voltada para aplicabilidade, ele pouco consegue levar o que aprende na licenciatura para sua realidade em sala de aula. O estágio está aí, para provar isso. Os alunos têm pavor do estágio, principalmente por saberem que estarão sendo observados pelos alunos, pelo professor regente, pelo professor de estágio. Bate uma total insegurança, pois eles não se sentem totalmente preparados pelo curso para ir à escola e enfrentar a realidade da sala de aula”. 


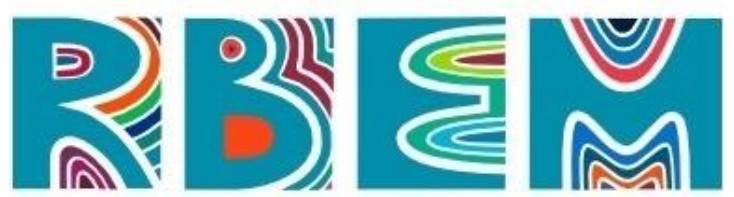

REVISTA BAIANA DE EDUCAÇÃO MATEMÁTICA

Com relação aos alunos estagiários, buscamos conhecer o papel do estagiário, bem como os efeitos do estágio na formação inicial do professor e sobre o desejo de ser professor de matemática. Aqui, nos preocupamos também, em relatar os aspectos éticos da pesquisa, os cuidados na elaboração dos termos de consentimento na garantia de sigilo aos depoentes e, sobretudo, a não identificação dos participantes.

Vale à pena acrescentar que durante a investigação realizada todos os materiais recolhidos para análise como relatórios, documentos diversos como questionários etc. foram obtidos dos sujeitos participantes da pesquisa, sendo eles professores, alunos, coordenadores de curso que não estavam em contato direto comigo, ou seja, por me encontrar afastada das atividades de ensino, combinei com os professores os encontros, os espaços para aplicação dos questionários etc. Os relatórios, por exemplo, foram produzidos por formandos que estavam no período do estágio sob supervisão de outros professores.

Esta análise identificou as condições que condicionam as práticas de ensino dos estudantes estagiários de Matemática, bem como, se organizam essas experiências de ensino nas escolas campo dos estágios, mesmo em tempos de ensino remoto emergencial.

\section{Com a palavra o professor}

Nesse sentido, enquanto professores, devemos ser capazes de utilizar instrumentos, ferramentas tecnológicas, estratégias de aprendizagem para atender um sistema, amplo e complexo de isolamento social imposto a todos os estudantes. O ECS tinha que responder a esse desafio. No geral, a sala de aula é um território de múltiplas e variadas experiências que envolvem desde os conhecimentos mais específicos das áreas, aos aspectos subjetivos, do exercício da profissão de professor. Nós professores, temos que lidar com mundos multifacetados no contato diário com os estudantes, com a comunidade escolar como um todo. Somos chamados a lidar com uma lógica docente que atravessa todos os limites, lógica essa que vai além da didática, da psicologia. E, como estar preparado para responder os novos desafios? Quais as condições indispensáveis para realizar o ECS?

GATTI (2020) nos sinaliza que chegamos a um ponto de inflexão em que se percebe uma mudança de comportamento no gráfico da vida: no cenário atual agravaram-se as desigualdades sociais. Ao incluir os nossos estudantes não podemos excluí-los. É preciso justiça social na inclusão escolar. Educação é vida. O sentido de construir mais vidas, não é 


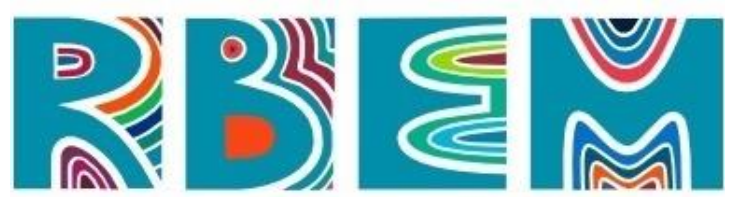

REVISTA BAIANA DE EDUCAÇÃO MATEMÁTICA

trivial. Agora, sobretudo, é o momento propício para os professores refletirem sobre a oportunidade de superarem uma pedagogia antiga baseada em modelos esgotados em si mesmo. Num cenário de medidas urgentes para novas práticas docentes, SANTOS (2020), faz lembrar que muitos de nós ainda vemos os estudantes como ignorantes vazios onde os professores enfiam o recheio do conhecimento. "A verdade é que se aprende-com e se ensinacom”. Nada é unilateral, tudo é recíproco.

Certo, que todos passaram por momentos na vida, em que sentimos que algo teria que mudar. Um ponto em que sentimos a necessidade de modificar um comportamento ou uma atitude, sob pena das coisas não funcionarem muito bem. Do ponto de vista matemático, as coisas não são muito diferentes. Façamos uma analogia com os fatos que estão acontecendo ao longo do ano de 2021: analisando um dos muitos gráficos da OMS, com os dados do avanço das infecções pelo COVID-19 conseguimos ver que estamos atravessando um momento muito complicado, uma vez que, à medida que o tempo passa, os números de infectados pelo vírus estão constantemente a aumentar. No entanto, estamos ansiosos por ler nos gráficos a presença de um ponto onde pareça que se passou algo, buscando inicialmente um platô, depois um decréscimo nos números de casos. De fato, a esperança desse ponto de inflexão, para que alguma coisa altere o comportamento de crescimento da curva, como a produção, em larga escala, de uma vacina, por exemplo, é ansiosamente esperada.

Claro, que os matemáticos ao analisarem os gráficos não fazem isto por mera observação. Para determinar a localização precisa desse ponto de inflexão, faz-se o estudo da segunda derivada da função. Sabendo que o declive da reta tangente nesse ponto é nulo, é possível determinar com exatidão a existência de um ponto de inflexão. É o que estamos esperando. A Matemática nos permite essa leitura do mundo além dos números com os seus significados.

Dados recentes, divulgados pelo Instituto Brasileiro de Geografia e Estatística (IBGE) da Pesquisa Nacional por Amostra de Domicílios (PNAD) referente ao ano de 2019, revelam que 4,6 milhões de pessoas, na Bahia tiveram que abandonar os estudos antes de concluir o Ensino Fundamental. Segundo dados PNAD, o índice de baianos não concluintes do Ensino Fundamental corresponde a 49,3\%, sexto maior percentual do país, acima da média nacional de 38,7\%. Em relação ao Ensino Médio, quase $60 \%$ dos baianos não concluíram essa etapa dos estudos. E, no Ensino Superior, só $11 \%$ concluiu a graduação. A OMS estima que a 


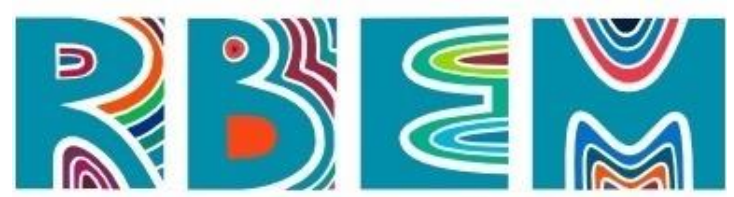

REVISTA BAIANA DE EDUCAÇÃO MATEMÁTICA

pandemia possa retirar 9,7 milhões de crianças da escola até o final do ano de 2020. Diante desses dados a educação sofrerá consequências desastrosas em todos os sentidos. Se antes do agravamento do quadro da pandemia, tínhamos resultados como os revelados pelo PNAD de 2019, com certeza os problemas se agravarão se não estancarmos esse quadro.

É certo que mesmo com trabalhos remotos, home offices todas as outras profissões deslocaram-se para um trabalho já conhecido por todos, em um ambiente diferente, por certo, com muitas variáveis, porém apesar do stress, do isolamento social as rotinas foram adaptadas ao momento que estamos vivendo. Rotinas de médicos, enfermeiros, ajudantes foram incrivelmente aumentadas, os que estão nos pontos de serviços essenciais trabalhando em farmácias, supermercados, bancos e outras instituições estão perigosamente expostos sem os cuidados necessários para evitar o contágio. E agora? E, nós os professores? Lançados a uma carga de trabalho que nos desafia, sobretudo, porque não temos experiências de ficar sem a presença dos alunos, o movimento das aulas, da escola e estamos assustados porque precisamos enfrentar e repensar dia a dia, o nosso modo novo de estar em contato com esses alunos, incorporando novas formas de atuação, aulas online etc.

E as universidades?

Para SANTOS (2020), poucas instituições estarão tão ameaçadas. Entretanto, nenhuma será tão importante para ajudar a sociedade pensar um mundo regido por novas lógicas, porém segundo ele para transformar, a universidade precisará revolucionar-se. Esse desafio foi posto para todos os professores. É tempo para planejar, (re)planejar, tomar decisões à luz das políticas públicas de todas as ordens, seja de saúde (o principal motor da vida) à educação urgente, para tempos prementes. A educação do futuro está acontecendo no presente. Nunca se viu tantas mudanças e transformações, no espaço docente, em tão pouco tempo. Inovar ganhou sentido nos dias de hoje, para responder desafios de lidar com as possibilidades que as tecnologias oferecem e a adoção de estratégias de ensino para os professores.

Os anos de 2020 e 2021 estão afetados definitivamente pela pandemia. Os professores precisarão passar continuamente por qualificação e treinamento para usar ferramentas digitais. Descuidou-se totalmente a situação dos professores, cobrados para realização de aulas online, atividades inclusivas, adaptadas ou especialmente concebidas para os novos formatos, utilizando recursos e meios próprios, acesso à internet e familiaridade com as tecnologias de 


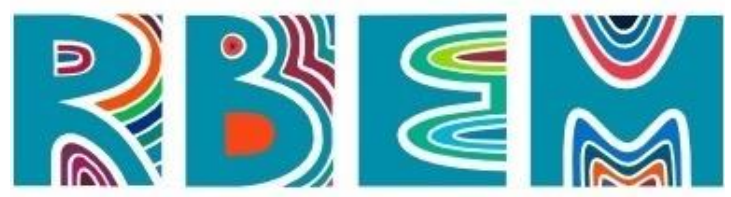

REVISTA BAIANA DE EDUCAÇÃO MATEMÁTICA

ensino com que a maioria estava pouco acostumada. Trabalhos ininterruptos, cargas horárias não computadas e de uma burocracia imensa, influenciando as alterações na vida familiar.

Com tudo isso, a procura de garantir a qualidade do processo de ensino e aprendizagem, o trabalho docente acumula sobrecarga e desgaste laboral indevidos no cenário atual onde as atividades remotas, o que sabemos, não caracteriza o modelo de ensino à distância (EAD), entretanto, a vontade de inovar quase por necessidade ante os desafios da pandemia, assustados com a imprevisibilidade do momento, contudo, nos afeta. O desafio está posto para todos: precisamos de outras formas de pensar o global e o local.

\section{Com a palavra os estagiários, futuros professores}

Ensinar é atividade complexa, o professor não atua no vácuo, por isso temos que ampliar nosso repertório além dos conteúdos programáticos da nossa disciplina. É preciso pensar, como bem coloca (GATTI, 2020), em voarmos como águias, buscar as generalizações, o global, o além do local, do que nos é familiar e aos nossos alunos. Sejam as referências da família, da comunidade de pertença e o que a escola nos apresenta.

Ser professor de Matemática é estabelecer relações com o ensinar funções, progressões, análise combinatória etc., mas também com a filosofia, a história, a antropologia, a psicologia, a sociologia, pois não poderá ser um bom professor de Matemática aquele que souber somente Matemática. Trata-se de um longo caminho a percorrer, pois o estado de pandemia lançou os professores, com as escolas fechadas, a ficarem sentados em frente ao computador, atentos às janelinhas na tela. Se antes tínhamos os espaços de descontração em sala de aula, dizem os especialistas, agora à parte cognitiva fica em constante estado de atenção.

Estabelecer um contato, uma conversa, na sala de aula virtual deve-se começar por colocar algumas ideias básicas do conteúdo que se vai trabalhar. No caso específico, da Matemática propor um problema, discutir estratégias e caminhos para a sua solução. Certamente, outras ideias vão se opor a transposição da aula tradicional, de quadro e giz para o mundo virtual. Não faz sentido filmar aulas ou mesmo transmitir aulas com essa metodologia tão criticada. É preciso mais. 


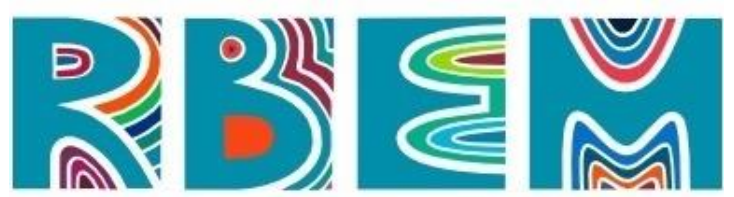

REVISTA BAIANA DE EDUCAÇÃO MATEMÁTICA

Aulas investigativas, desafiantes e modeladas para despertar o interesse dos estudantes requerem também abordagens generalistas. Situadas dentro de um contexto sociocultural, com o exercício do pensamento crítico podemos encontrar caminhos para o ensino de Matemática em ambientes virtuais. A pandemia e o isolamento social estão a revelar que são possíveis alternativas, que as sociedades se adaptam a novos modos de viver quando tal é necessário, e sentido como correspondendo ao bem comum. Esta situação torna-se propícia a que se pense em alternativas ao modo de viver, de produzir, de consumir e de conviver nestes primeiros anos do século XXI (SANTOS, 2020).

Entretanto, desde a suspensão das diversas atividades acadêmicas, em particular, com o fechamento das escolas, pois, a pandemia atingiu todos os setores como a economia, a saúde, e a educação, esta última impactada pelas restrições e impedimentos impostos pela necessidade do isolamento social, com aulas presenciais suspensas em todos os níveis, da educação infantil à pós-graduação. Faz-se necessário refletir sobre a realização de aulas, atividades, eventos de ensino e aprendizagem remota. Queremos provocar e instigar debates com a ponderação do que vem sendo posto nas redes sociais, principalmente. A discussão sobre inclusão social foge a nossa intenção nesse artigo, pois a pandemia revelou ainda mais a desigualdade social e não desconhecemos que a maioria dos nossos estudantes pertencem à classe menos favorecida socialmente.

É dever urgente das instituições públicas e privadas promover os meios de acesso possíveis a todos os estudantes, sejam na oferta de ferramentas como computadores, tabletes etc., com o devido provimento das condições necessárias à atividade remota, pelo acesso aos recursos que devem ser disponibilizados pelo sistema, tanto os dados de internet quanto os dispositivos eletrônicos. Queremos debater formas de retorno de atividades de ensino possíveis de serem desenvolvidas de forma remota, resguardando o direito de todos.

Com relação ao ensino da Matemática em pesquisa recente, realizada nos meios eletrônicos com o auxílio da internet, constatamos a oferta de cursos gratuitos de formação continuada de professores, para a utilização dos recursos tecnológicos. O parecer do MEC ressalta que $86 \%$ dos docentes sentem-se inseguros em utilizar na regência, recursos tecnológicos e esse número se eleva com o fator idade. Instituições como a Universidade Federal do Rio de Janeiro (UFRJ) dentre muitas, oferecem cursos de extensão gratuitos para os professores, outros cursos, oferecem resumos, desafios, sugestões diversas para alunos e 


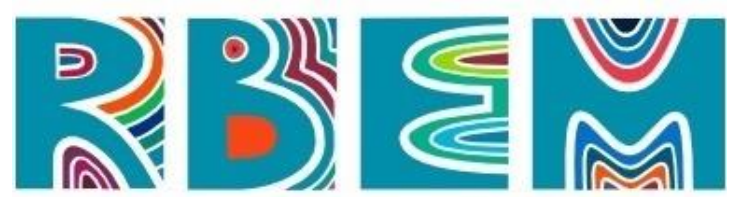

REVISTA BAIANA DE EDUCAÇÃO MATEMÁTICA

professores nesse período de pandemia. Aulas online ministradas por professores e, além disso, oferecendo apoio com atendimento individual.

Em um tempo de isolamento social, os ambientes virtuais possibilitam a utilização de ferramentas de comunicação, o contato com os alunos. Conectar os alunos com o objetivo da aprendizagem sendo essa fase muito importante: a motivação. Criar um desequilíbrio para motivar os alunos. O uso de atividades investigativas, da História da Matemática, a resolução de problemas colocados em primeiro plano, a discussão, a descoberta. Dirigir e focalizar a atenção dos alunos. O uso de perguntas, criar expectativas para que os alunos se sintam motivados, a participar, a interagir. As tarefas investigativas no ensino da Matemática proporciona uma abordagem pelo professor para a realização de atividades de análise, reflexão e generalização.

Aulas virtuais, os recursos que podemos oferecer para os alunos, favorece a aquisição de conhecimentos matemáticos. Trabalhar com mapas conceituais (ligando e conectando conteúdos antigos com os novos). Trabalhar com sequências didáticas investigativas. Fazer e responder a perguntas para possibilitar ao aluno aprender, o cerne de um conceito, suas implicações, sua história, suas aplicações em contextos significativos.

Organizar as informações relacionando-as com outras estruturas. Dar um colorido emocional às atividades, trabalhar com a percepção seletiva dos estudantes. Bom senso para fazer demonstrações breves, "modelar" o processo de pensamento e reflexão para sugerir evidências. Incluir referências a fatos e aspectos reais, divertidos, engraçados. Aplicar o conhecimento construído a situações novas. Tutoriais escritos e em vídeos, aproveitando as experiências dos alunos e as vivências. Usar figuras, gráficos, outras formas de representação visual que ajudem a ilustrar as atividades, animações prontas etc. além de sempre dar feedback construtivo aos estudantes.

O emprego de tecnologias da informação no ambiente de ensino virtual pode ser a forma de se estabelecer uma revolução na comunicação pedagógica e nos modos de aprendizagem. Sobre os desafios que se colocam sobre os professores no aprender e ensinar, em espaços de aprendizagem por meio da internet, destaca a utilização de tecnologias síncronas ou assíncronas exigem que todos os envolvidos participem juntos, ao mesmo tempo, embora não seja no mesmo local, no caso das síncronas, por meio de Google Meat e Lives no Instagram. E as tecnologias assíncronas, com os recursos digitais específicos permitem que os 


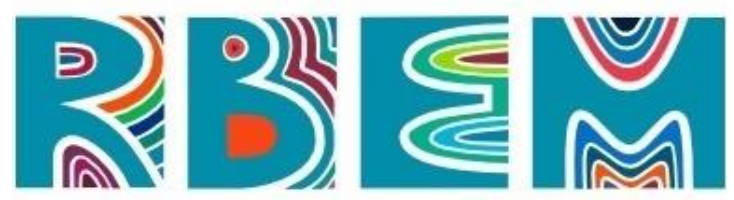

REVISTA BAIANA DE EDUCAÇÃO MATEMÁTICA

participantes acessem materiais ou se comuniquem em diferentes momentos por meio de mídias gravadas, vídeos, fóruns de discussões, painéis etc.

O empenho dos estudantes em realizar as atividades é reflexo da interface atrativa da plataforma e do enfoque interdisciplinar dado. A tecnologia utilizada representa uma importante ferramenta de ensino, considerando os vários recursos que oferece para resolução de problemas matemáticos; sua disponibilidade universal e ambiente de trabalho que estimulam o uso. As atividades elaboradas no âmbito do trabalho, de fato, contribuem para o ensino e a aprendizagem dos estudantes.

\section{Reflexões conclusivas}

São muitas informações, porém precisamos antes de tudo definir objetivamente o que queremos. Estamos discutindo e apresentando os resultados dos conhecimentos adquiridos na prática, em projetos, estudos que vêm sendo implantados pelas instituições de ensino no país, como alternativa para a continuidade dos estudos em tempos de pandemia.

Por outro lado, temos um desafio imenso quando a sociedade discrimina portadores de necessidades especiais, estudantes que não possuem computadores, nem acesso a internet e quando estamos buscando melhorar o ensino à distância. Temos que reconhecer os limites desse processo enquanto estamos falando de acesso a recursos e condições que permitam a todos desfrutar da sociedade como qualquer outra pessoa. Modelos que não incluir todos e ignorar os princípios de equidade, de cidadania e os direitos humanos não são justos. Entretanto, há uma luz no fim do túnel e SANTOS (2020), diz que a pandemia e a quarentena estão a revelar que são possíveis alternativas, que as sociedades se adaptam a novos modos de viver quando tal é necessário e sentido como correspondendo ao bem comum.

Essencial destacar o processo da formação inicial do futuro professor de Matemática que passa por profundas mudanças no cenário da profissão de professor dessa mesma disciplina a partir de um conjunto de fatores impactados pela legislação, pelos novos projetos curriculares dos cursos, as novas demandas da sociedade, incluindo-se as expectativas das escolas em relação ao ensino-aprendizagem da Matemática.

Face o estudo realizado, a situação revelada está longe de ser caracterizada como ideal. São inúmeras as dificuldades, tensões e problemas enfrentados pelos estudantes e 


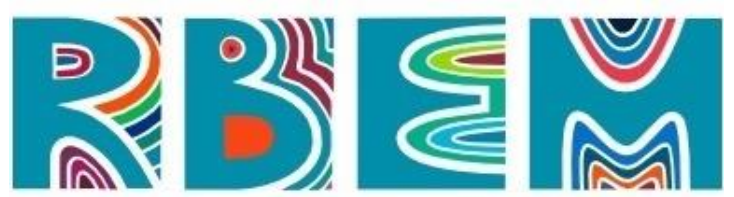

REVISTA BAIANA DE EDUCAÇÃO MATEMÁTICA

professores no dia a dia, nos cursos de formação de professores de Matemática e das escolas públicas. Essas mesmas deficiências foram reveladas através das análises dos diferentes documentos construídos na pesquisa, tais como, questionários, entrevistas, memoriais dos professores, e relatórios.

As mudanças que estão acontecendo de maneira bem diferenciada nos cursos pesquisados de Licenciatura em Matemática, representam uma forte tendência dessas e de outras instituições de superar um modelo de formação de professores de Matemática. Modelos esses pautados numa inspiração cartesiana, a partir de uma racionalidade técnica, meramente instrumental para um novo modelo de formação dentro de um paradigma humanístico da concepção pedagógica dos cursos. Trata-se de uma tendência presente nos projetos pedagógicos dos cursos pesquisados neste estudo, que vem reverberando no conjunto do seu funcionamento, envolvendo professores, estudantes, apesar do número reduzido de cursos analisados, ou seja, três cursos de Licenciatura em Matemática. Destaco, entretanto, a amplitude da análise realizada do conjunto de dados produzidos na pesquisa frente à grandeza das IES pesquisadas para o estudo. Um ponto importante do estudo sobre a aprendizagem escolar em Matemática é influenciada por aspectos sociais e epistemológicos, num movimento de apropriação e transformação contínua dentro da sala de aula, na escola ou em qualquer outro ambiente formal ou não formal de ensino, conforme as observações in lócus nas universidades e nas escolas visitadas. É essa aproximação com fatores sociais, culturais e epistemológicos que influenciam as práticas docentes de estagiários e professores iniciantes enquanto construção de conhecimento nos processos de formação, por isso, enfatizei o papel da prática social na pesquisa, trabalhando com a Socioepistemologia.

Nesse sentido, as propostas de estágios das instituições são convergentes e distanciadas em vários aspectos:

- Os resultados dos novos projetos pedagógicos dos cursos de licenciatura em Matemática, provocaram o mínimo de alteração nas características estruturais dos estágios curriculares supervisionados, excetuando-se aquelas de caráter normativo imposto por força de lei, como no caso do aumento da carga horária do estágio curricular nos cursos.

- As iniciativas individuais dos professores supervisores do estágio, constituem diferencial para a qualidade da formação oferecida no sentido de contemplarem as competências e habilidades listadas nos projetos pedagógicos para os egressos dos cursos de graduação, 


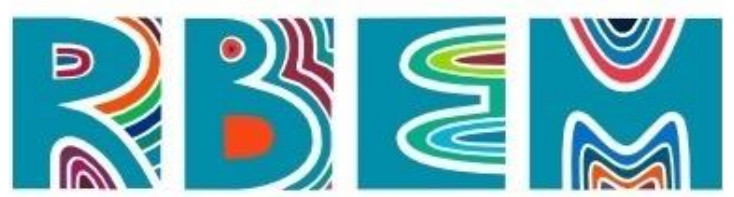

REVISTA BAIANA DE EDUCAÇÃO MATEMÁTICA

inspiradas nas diretrizes curriculares para os cursos de licenciatura em Matemática, o que denota uma ausência do coletivo dos professores dos cursos, no que tange ao alcance dos objetivos igualmente propostos em todos os projetos pedagógicos analisados.

- As diretrizes curriculares para a formação de professores não se constituem em referências que ultrapassem o estabelecido nos documentos para o efetivo papel de serem apropriadas pelos professores, de forma crítica e capaz de provocar mudanças mencionadas pelos professores, quando questionados sobre a qualidade da formação dos futuros professores de Matemática.

Destacamos, por meio da análise dos dados coletados, indicadores que demonstraram a preocupação das IES em atenderem as orientações das Diretrizes Curriculares Nacionais de Formação de Professores, bem como, as orientações das Diretrizes Curriculares Nacionais para os Cursos de Matemática, Bacharelado e Licenciatura (Parecer CNE/CES 1.302/2001) adequando os currículos dos cursos de Licenciatura em Matemática.

Os projetos pedagógicos são ambiciosos e, não conseguiram sair do papel. As novas orientações pedagógicas contidas nesse documento, as mudanças preconizadas para substituição das atividades consideradas "tradicionais" no ECS, de fato, não ocorrem, predominando nos cursos uma visão fragmentada e desarticulada do processo de formação do professor de Matemática, em detrimento de uma real integração de professores de disciplinas numa perspectiva crítica, reflexiva e de pesquisa, excetuando-se para os casos isolados das iniciativas de professores supervisores do ECS. Como também destaca (BARREIRO; GEBRAN 2006, p.15), quando se refere que os resultados de mudanças presentes na formação dos professores não são resultados dos projetos pedagógicos dos cursos de graduação, o que de fato foi constatado neste estudo.

Dessa forma, apesar dos projetos pedagógicos analisados sinalizarem para a necessidade de aproximar entre a formação inicial dos futuros professores de Matemática com a realidade escolar, o que percebemos não só na fala dos professores entrevistados, como também pela experiência profissional e nas visitas realizadas as escolas durante a realização da pesquisa, como também, nas conversas com os professores regentes que recebem os estudantes estagiários nas escolas de educação básica onde não existe essa articulação anunciada. Os projetos pedagógicos analisados não esclarecem como se dará essa relação entre a universidade e as escolas de educação básica, nem como será feito o acompanhamento 


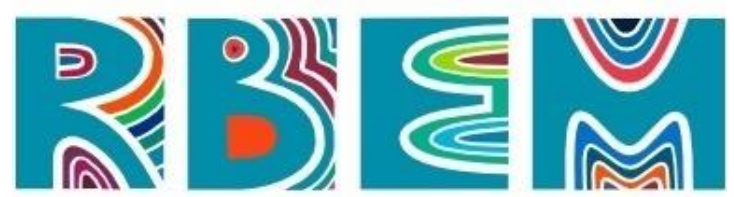

REVISTA BAIANA DE EDUCAÇÃO MATEMÁTICA

dos estudantes estagiários nas escolas campo de estágio, deixando subentendido que a responsabilidade do contato com as escolas, acompanhamento e supervisão é responsabilidade do professor supervisor do ECS.

Não existe articulação entre a universidade e o campo de estágio que é a escola, constatamos na pesquisa. O ECS é um período meio caótico, diz o professor entrevistado que trabalha em duas das instituições pesquisadas. Numa concepção efetiva de ECS, como momento de interação do professor da universidade, com o professor da escola é necessário dedicar mais tempo à escola, ao professor, ao aluno.

A carga horária do professor supervisor de ECS deveria ser concentrada na escola, interagindo com direção, professores e estudantes no contexto escolar. Isso teria um impacto muito significativo, podendo melhorar o currículo escolar, as metodologias de ensino de Matemática.

Pelo que foi argumentado até este momento, o ECS como atividade teórica e instrumental tem contado com contribuições de autores que se pautam pelos princípios da formação do profissional reflexivo, focado na pesquisa, na investigação como saída para a construção de um processo de formação do professor de Matemática com qualidade. As diretrizes curriculares, os projetos políticos pedagógicos, as mudanças ocorridas na formação de professores e os instrumentos de avaliação apontam, entretanto, caminhos interessantes para um novo perfil do Curso de Licenciatura em Matemática e da formação do professor de Matemática.

É preciso acompanhar esse movimento e tudo nos convida a participar, nesse momento fundamental, para refletir sobre essas conclusões do estudo.

Diante dos processos apontados aqui neste artigo sem a pretensão de esgotar temáticas temos uma preocupação: é preciso encontrar caminhos para romper com concepções de reprodução de conhecimento, de modelos que tem orientado a prática docente e o ECS na formação de professores, por outro lado, o incentivo a busca de metodologias inovadoras criativas tem funcionado mesmo diante do desafio do ensino remoto emergencial.

A pesquisa revelou que essa pressão que professores e os estagiários sofrem para inovar em sala de aula por parte dos professores supervisores não acompanha uma reflexão, uma discussão mais fundamentada sobre metodologias ou práticas inovadoras esvaziando-se completamente o sentido da introdução de metodologias consistentes, ancoradas numa 


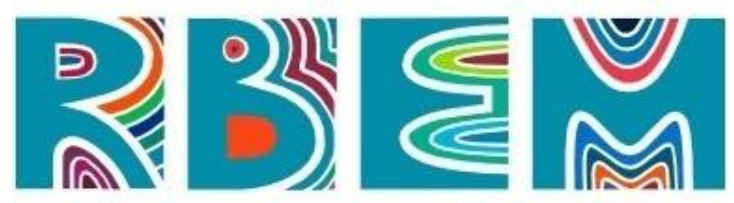

REVISTA BAIANA DE EDUCAÇÃO MATEMÁTICA

reflexão permanente sobre a prática sem contribuir para a transformação da realidade em que vai se atuar na escola.

Muitas dessas experiências “inovadoras", “criativas" são esvaziadas de sentido constituindo-se em ações absolutamente dispensáveis para o trabalho em sala de aula. A insegurança revelada pelos estagiários está muitas vezes associada à imaginação de sua presença na escola sem o trabalho adequado para exercer tal atividade, é como justifica um estagiário é "a falta de certas informações que o curso não transmite" digo, que o curso de LM não prepara, pois não concebe o estágio como um espaço no curso da formação inicial do professor de Matemática.

Essencial destacar o processo da formação inicial do futuro professor de Matemática no bojo dessas mudanças que impactaram a vida, a sociedade que passa por profundas mudanças em virtude de um conjunto de fatores impactados pelas demandas da sociedade, incluindo-se as expectativas das escolas em relação ao ensino-aprendizagem da Matemática em um período pandêmico.

Em face do estudo realizado, a situação revelada está longe de ser caracterizada como ideal. São inúmeras as dificuldades, tensões e problemas enfrentados pelos estudantes e professores no dia a dia seja, nos cursos de formação dos professores de Matemática ou nas A escolas públicas. Para encerrar, gostaria de destacar que até o momento, houve poucos avanços nos cursos de Licenciatura em Matemática para a melhoria da qualidade do ensinoaprendizagem de Matemática nas escolas pesquisadas, mesmo em tempo de pandemia, de ensino remoto, as mudanças ocorridas nas práticas das professoras regentes, os trabalhos desenvolvidos pelos estudantes estagiários deixam a desejar, pois, provocam poucas alterações no ritmo das escolas, principalmente, nas salas de aulas, no ensino de Matemática, entretanto, isso não ocorre nas turmas de todos os estagiários. Alguns desses estudantes, ainda, permanecem presos ao paradigma da racionalidade técnica, no exercício de suas atividades docentes, talvez como alguns dos indicadores da pesquisa sinalizam, pelo conservadorismo de métodos e técnicas de ensino de Matemática privilegiados pelos professores do curso, na graduação.

Percebo, entretanto, que alguns aspectos precisam ser repensados: a competência básica de todo professor e, consequentemente, as mudanças pedagógicas produzidas em sala de aula passam pelo domínio do conteúdo específico de Matemática. Somente a partir desse 


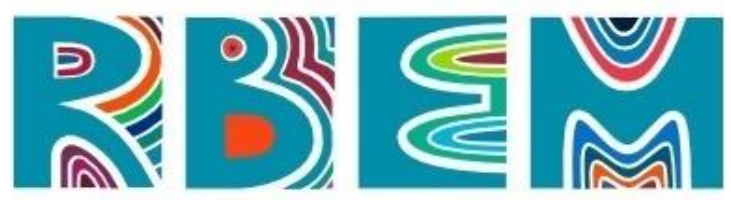

REVISTA BAIANA DE EDUCAÇÃO MATEMÁTICA

conhecimento básico, específico, é possível construir e produzir ações educativas competentes, o que não significa que mudanças não possam ocorrer na formação do professor de Matemática. O ECS representa essa possibilidade concreta para as mudanças na formação inicial, desde que o ECS represente de fato, não a explicitação da fragmentação do curso de Licenciatura, como vem ocorrendo na prática. Como o ECS tem sido concebido nessas instituições de ensino: uma etapa da formação inicial, separada do curso. Uma atividade de caráter obrigatório, de responsabilidade exclusiva do professor supervisor do estágio. Não é mais possível tratar o ECS como um apêndice do curso de Licenciatura em Matemática.

Nesse sentido, este estudo recomenda que os esforços para a melhoria da qualidade do ensino de Matemática devem ocorrer fundamentalmente na escola, na universidade e devem envolver todos os docentes do curso de Licenciatura em Matemática, os professores das escolas de Educação Básica contemplando e valorizando o saber docente formado e aperfeiçoado no cotidiano da escola.

O lócus da formação a ser privilegiado é a escola e, como fala (CANDAU, 1996, p.143), "considerar a escola como lócus de formação inicial do futuro professor de Matemática passa a ser uma afirmação fundamental na busca de superar o modelo clássico de formação inicial dos professores e construir uma nova perspectiva na área de formação de professores".

É cabível a revisão dos projetos pedagógicos e dos currículos considerando a dinâmica de uma sociedade em mudança, ajustando-os as suas demandas e anseios, redefinindo o papel do professor de Matemática egressos dos cursos de Licenciatura.

Este momento em especial, coloca todos os educadores no mesmo barco para pensar alternativas no modo de aprender e ensinar, refletir sobre o nosso Planeta, nossa civilização nestes primeiros anos do século XXI.

No atual contexto de discussão sobre a formação de professor e de construção de um projeto de educação de qualidade, a reflexão sobre o Estágio Curricular Supervisionado (ECS) ganha relevância, na medida em que pode contribuir de fato para a melhoria da formação do professor de Matemática que deve estar sintonizado com as mudanças e os avanços da sociedade em geral, que cobra mudanças de concepções de ensino-aprendizagem de Matemática, de práticas, de técnicas de ensino em coerência com a dinâmica do mundo atual. 


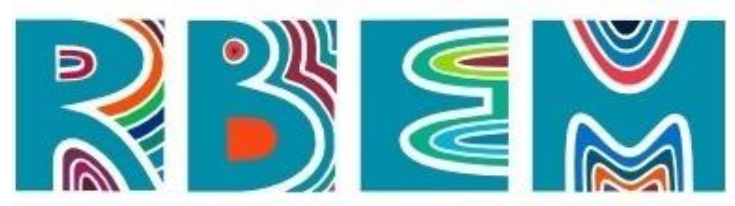

\section{Referências}

BARREIRO, Iraíde Marques de Freitas; GEBRAN, Raimunda Abou. Prática de Ensino e Estágio Supervisionado na Formação de Professores. São Paulo: Avercamp, 2006.

BRASIL. Resolução $\mathrm{N}^{\mathrm{o}} 2$, de $1^{\circ}$ de julho de 2015. Define as Diretrizes Curriculares Nacionais para a formação inicial em nível superior (cursos de licenciatura, cursos de formação pedagógica para graduados e cursos de segunda licenciatura) e para a formação continuada.

Disponível em http://portal.mec.gov.br/index.php?option=com_docman\&view=download\&alias=17719rescne-cp-002-03072015\&Itemid=30192. Acessado em: 29 mar. 2019

CANDAU, Vera Maria (Org.). Magistério: construção cotidiana. Petrópolis, RJ: Vozes, 1996.

GATTI, Bernadete A. [LIVE] Formação Continuada Territorial. Disponível em https://youtu.be/ke8qMlZU6T4. Acesso em:07 de jul. de 2020 \#FicaEmCasa \#EstudeEmCasa \#ProgramaBahiaOlimpica.

GARCÍA, Marcelo Carlos. Formação de Professores: para uma mudança educativa. Colecção Ciências da Educação: século XXI. Porto: Porto, 1999.

MERTON, Robert K. Sociologia do conhecimento. In: Sociologia do Conhecimento.

SANTOS, Boaventura de Sousa. Outras palavras além da mercadoria. Disponível em https://outraspalavras.net/alemdamercadoria/boaventura-a-universidade-pos pandemica. Acesso em: 02 jul.2020.

SANTOS, Boaventura de Sousa. A Cruel Pedagogia do Vírus. Edições Almedina, Coimbra, Portugal, 2020.

Artigo submetido em: 30/06/2021

Artigo aceito em: 24/08/2021 